\title{
Ocular lesions in hereditary hemorrhagic telangiectasia: genetics and clinical characteristics
}

\author{
Inés Gómez-Acebo 1,2,3* (D), Sara Rodríguez Prado ${ }^{2,4}$, Ángel De La Mora ${ }^{2,4}$, Roberto Zarrabeitia Puente ${ }^{2,5,6}$, \\ Beatriz de la Roza Varela ${ }^{4}$, Trinidad Dierssen-Sotos ${ }^{1,2,3}$ and Javier Llorca ${ }^{1,2,3}$
}

\begin{abstract}
Background: The aim of our study is to study the association between eye lesions in Hereditary Hemorrhagic Telangiectasia (HHT) and other signs of the disease, as well as to characterize its genetics.

Methods: A cross-sectional study was conducted of a cohort of 206 patients studied in the HHT Unit of Hospital de Sierrallana, a reference centre for Spanish patients with HHT. Odds ratios for several symptoms or characteristics of $\mathrm{HHT}$ and ocular lesions were estimated using logistic regression adjusting for age and sex.

Results: The ocular involvement was associated with being a carrier of a mutation for the ENG gene, that is, suffering from a type $1 \mathrm{HHT}$ involvement $(\mathrm{OR}=2.09 ; 95 \% \mathrm{Cl}$ [1.17-3.72]). $p=0.012)$. In contrast, patients with ocular lesions have less frequently mutated ACVRL1/ALK1 gene (OR=0.52; $95 \% \mathrm{Cl}[0.30-3.88], p=0.022)$.

Conclusions: In conclusion, half of the patients with $\mathrm{HHT}$ in our study have ocular involvement. These eye lesions are associated with mutations in the ENG gene and ACVRL1/ALK1 gene. Thus, the ENG gene increases the risk of ocular lesions, while being a carrier of the mutated ACVRL1/ALK1 gene decreases said risk.
\end{abstract}

Keywords: Hereditary hemorrhagic telangiectasia, HHT, Osler-weber-Rendu, ENG, ACVRL1/ALK1

\section{Background}

Hereditary hemorrhagic telangiectasia (HHT) or RenduOsler-Weber syndrome is a rare disease that affects between 5000 to 8000 people worldwide [1], although, given the clinical variability of the disease and subclinical forms, it is believed that the figures are underestimated. The HHT presents a wide geographic variability, the highest prevalence rate being among the Afro-Caribbean population of the islands of Curaçao and Bonaire, with 1 case in 1331 inhabitants due to a probable founder effect [2].

\footnotetext{
* Correspondence: ines.gomez@unican.es

${ }^{1}$ Facultad de Medicina, Universidad de Cantabria, Avda. Herrera Oria s/n, 39011 Santander, Spain

${ }^{2}$ IDIVAL, Santander, Spain

Full list of author information is available at the end of the article
}

HHT is characterized by the presence of vascular malformations; its diagnosis is based on Curaçao's clinical criteria: recurrent epistaxis, multiple telangiectases in skin and mucosae, visceral involvement (including, for instance, arteriovenous malformations in lung, brain or liver) and first degree relative with HHT. Three or four criteria need to be fulfilled for the diagnosis to be established [3]. HHT is inherited with an autosomal dominant pattern. Approximately $75 \%$ of cases are caused by mutations in the Endoglin (ENG) gene, responsible for the HHT1 subtype, and ACVRL1ACVRL1/ALK1(activin A receptor like kinasa type 1), responsible for the HHT2 subtype. About $1-3 \%$ of patients with a clinical diagnosis or $10 \%$ of patients with a negative genetic test for ENG and ACVRL1/ALK1are carriers of mutations in the MADH4 (mother against decapentaplegic homolog 4) 
gene, that codifies for Smad 4 $[4,5]$. The HHT Subtype also has geographical preferences, with HHT1 being more frequent in North America $[6,7]$ and in northern Europe [8], while HHT2 is more prevalent in Mediterranean countries like Italy [9, 10], France [11] and Spain [12].

Although eye involvement is frequent, few studies have described its characteristics and its relationship with other HHT features [13-17], and they were purely descriptive. The main goal of this paper is to study the association between eye lesions in HHT and other signs of the disease, as well as to characterize its genetic background. In order to do it, we carried out a crosssectional analysis of a cohort of 206 patients studied in the HHT Unit of Hospital de Sierrallana, Spain.

\section{Methods}

\section{Setting and patients}

The study was conducted in the HHT Unit of the Sierrallana Regional Hospital (Torrelavega, Cantabria), Spanish national reference centre for HHT. Patients were included if they have a confirmed diagnosis of HHT according to Curaçao criteria and/or genetic test between March 2003 and September 2013. Patients who do not reside in Spain or without Spanish nationality have been excluded from the analysis. All patients were screened by the Ophthalmology Department to assess the presence of ocular lesions associated with HHT.

All procedures performed in studies involving human participants were in accordance with the ethical standards of the institutional and / or national research committee, and with the 1964 Helsinki Declaration and its later amendments or comparable ethical standards. The specific study reported here was approved by the Ethical Committee of Clinical Research of Cantabria. Informed consent was obtained from all individual participants included in the study.

\section{Diagnosis procedure (Fig. 1)}

Patients accomplishing 3 or 4 Curaçao criteria were diagnosed as HHT. Patients fulfilling only 1 or 2 Curaçao criteria were diagnosed as HHT only if they also carried a mutation in ACVRL1/ALK1, ENG or MADH4 genes.

\section{Genotyping procedure (Fig. 1)}

All patients were genotyped searching for mutations in ACVRL1/ALK1, ENG and MADH4 genes; if all three genotyped were negative, multiplex ligation-dependent probe amplification (MLPa) techniques were performed to rule out deletions / insertions in ACVRL1/ALK1 and ENG. Results of all genetic tests were compared with the international database of HHT mutations [18] to check whether they were mutations already described or they were new.

\section{Ophthalmologic examination}

All patients were studied in the Ophthalmology service. In the ophthalmological examination, the best corrected visual acuity, the palpebral physical examination and the anterior ocular segment have been assessed by means of a slit lamp, including upper eyelid eversion. The ocular tension was measured by contact tonometry and the

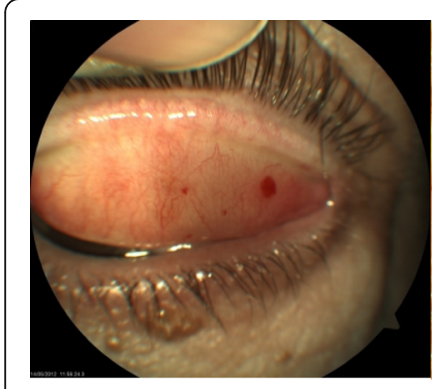

tarsal conjunctiva

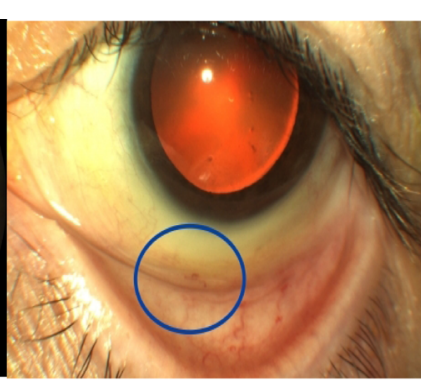

bulbar conjunctiva

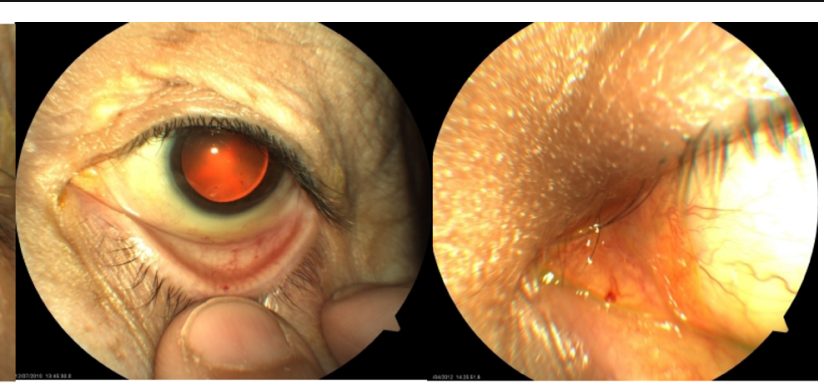

lid margin caruncle

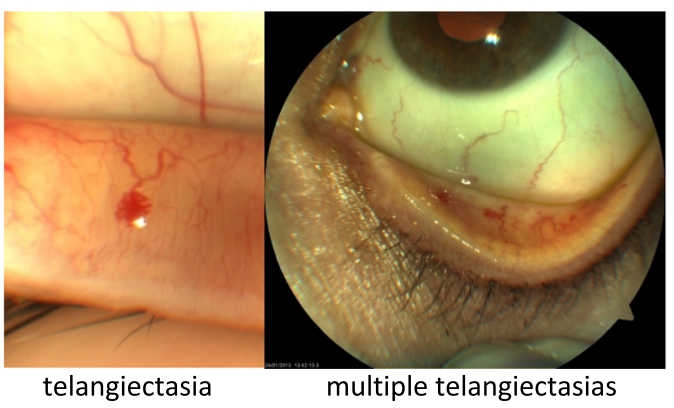

Fig. 1 Location of ocular telangiectasia in patients with $\mathrm{HHT}$ 
fundus was explored under mydriasis by indirect ophthalmoscopy. In case of injuries, these were photographed.

\section{Other tests}

All patients underwent physical examination, family tree scrutiny and search for vascular malformations by cerebral MRI angiography, conventional and contrast (bubbles) echocardiography, conventional abdominal ultrasound, abdominal Doppler to study hepatic vascularization and capillaroscopy evaluating megacapillaries and microhemorrhages in the nail bed of the 4th and 3th fingers of the right hand. All patients were studied in the Otolaryngology service. All patients also received the Quality of Life Scale (Euroqol 5D) and exclusively for women of childbearing age, a lumbar MRI angiography was also performed.

Other explorations could be carried out depending of the results of the previous tests, including thoracic CT with or without intravenous contrast, CT angiography, abdominal $\mathrm{CT}$ and pulmonary angiography.

\section{Statistical analysis}

For the description of the main qualitative variables, proportions were used. Quantitative variables were described by mean and standard deviation (SD). To quantify the degree of association between the variables, raw and age- and sex-adjusted odds ratios (OR) with their 95\% confidence interval $(95 \% \mathrm{CI})$ were estimated via logistic regression. In all the statistical tests used, a value of $p<0.05$ was considered statistically significant. Stata 14 / SE package was used in the analyses.

\section{Results}

\section{Characteristics of patients}

Table 1 displays demographic characteristics and distribution of ocular involvement. Out of 206 patients with confirmed HHT, 105 (51\%) had ocular telangiectasias on the examination performed by ophthalmologists. Patients with ocular involvement were older on average ( $50.3 \pm 13.5$ vs. $44.7 \pm 15.7, p=0.006)$. Eye lesions did not affect visual acuity or intraocular pressure. Fifty-five patients had both eyes affected; most ocular telangiectasias were located in the tarsal conjunctiva and fewer were located in bulbar conjunctiva, lid margin and caruncle; no lesions were found in retina. Figure 1 shows pictures with different locations of ocular telangiectasias. Regarding the exploration with slit lamp and ophthalmoscopy, we found no differences between patients with and without ocular involvement. Eye involvement was not associated with the accomplished criteria of Curaçao (Table 2). Regarding the association between the patient's personal history and ocular involvement (supplementary Table 1) we observe that there are no
Table 1 Demographic data and eye involvement of patients with HHT

\begin{tabular}{|c|c|c|c|}
\hline & Eye involvement & No eye involvement & $\boldsymbol{p}$ value \\
\hline \multicolumn{4}{|l|}{ Sex } \\
\hline Men & $48(49.5 \%)$ & $49(50.5 \%)$ & 0.69 \\
\hline Women & $57(52.3 \%)$ & $52(47.7 \%)$ & \\
\hline Age: mean $\pm s d$ & $50.3 \pm 13.5$ & $44.7 \pm 15.7$ & 0.006 \\
\hline$<19$ years & $1(11.1 \%)$ & $8(88.9 \%)$ & 0.05 \\
\hline 20-39 years & $24(45.35)$ & $29(54.7 \%)$ & \\
\hline $40-59$ years & $53(55.2 \%)$ & $43(44.8 \%)$ & \\
\hline $60-79$ years & $27(56.3 \%)$ & $21(43.7 \%)$ & \\
\hline \multicolumn{4}{|c|}{ Visual acuity: mean $\pm s d$} \\
\hline Right eye & $0.90 \pm 0.17$ & $0.93 \pm 0.18$ & 0.26 \\
\hline Left eye & $0.88 \pm 0.22$ & $0.94 \pm 0.21$ & 0.11 \\
\hline \multicolumn{4}{|c|}{ Intraocular pressure: mean $\pm \mathrm{sd}$} \\
\hline Right eye & $15.40 \pm 2.15$ & $15.80 \pm 2.17$ & 0.32 \\
\hline Left eye & $15.21 \pm 2.05$ & $15.66 \pm 2.03$ & 0.24 \\
\hline \multicolumn{4}{|c|}{ Laterality of ocular telangiectasias } \\
\hline Both eyes & 55 & & \\
\hline Right eye & 34 & & \\
\hline Left eye & 15 & & \\
\hline \multicolumn{4}{|c|}{ Conjunctiva location of telangiectasias: patients (no. of eyes) } \\
\hline Tarsal & $97(150)$ & & \\
\hline Bulbar & $2(2)$ & & \\
\hline Border & $6(7)$ & & \\
\hline Caruncle & $1(1)$ & & \\
\hline \multicolumn{4}{|c|}{ Eyelid location of telangiectasias: patients (no. of eyes) } \\
\hline Upper and lower & $18(30)$ & & \\
\hline Upper & $32(42)$ & & \\
\hline Lower & $23(32)$ & & \\
\hline
\end{tabular}

statistically significant differences between patients with arterial hypertension or diabetes mellitus and ocular involvement. Mutations in ACVRL1/ALK1 gene appeared in 118 patients (57\%) and in Endoglin gene in 77 patients (37\%). Eye involvement was twice as frequent in patients carrying a mutation in the Endoglin gene than in patients with mutation on the ACVRL1/ALK1 gene (Odds ratio $[\mathrm{OR}]=2.10,95 \%$ CI: $1.12-3.95)$ (Table 3).

The more frequent locations for telangiectasias -apart from conjunctiva- were nose (192, 93\%), lips $(166,81 \%)$, mouth $(156,76 \%)$ and fingers $(128,62 \%)$. Ocular telangiectasias were associated with telangiectasias in fingers (age and sex adjusted OR $=2.25,95 \%$ CI: 1.21-4.17, $p=$ $0.01)$, but not with telangiectasias in other locations as nasal, labial, oral or trunk (Table 4). As with the association of ocular involvement and the presence of telangiectasias in the fingers, ocular lesions in HHT have a significant association with capillaroscopy, multiplying 
Table 2 Eye involvement association with diagnostic criteria of Curaçao

\begin{tabular}{llll}
\hline Curaçao criteria & & Eye involvement & No eye involvement \\
\hline Telangiectasias & No & $0(0 \%)$ & $0(0 \%)$ \\
Epistaxis & Yes & $105(100 \%)$ & $101(100 \%)$ \\
& No & $1(0.95 \%)$ & $3(2.97 \%)$ \\
Visceral lesions & Yes & $104(99.05 \%)$ & $98(97.03 \%)$ \\
& No & $22(20.95 \%)$ & $27(26.63 \%)$ \\
First degree relative affected & Yes & $83(79.05 \%)$ & $74(73.27 \%)$ \\
& No & $1(0.9 \%)$ & $1(1.0 \%)$ \\
Nositeria & Yes & $104(99.1 \%)$ & $100(99.0 \%)$ \\
& $\mathbf{1}$ & $0(0 \%)$ & $0(0 \%)$ \\
& $\mathbf{2}$ & $0(0 \%)$ & $1(1.0 \%)$ \\
\end{tabular}

by 2.26 the possibility of presenting a positive result $(\mathrm{OR}=2.26$; IC95\% [1.20-4.27] $p=0.004)$. This probability decreases if we adjust for age and sex $(\mathrm{OR}=1.99$; IC95\% [1.04-3.81]) but remains significant (Supplementary Table 4).

In relation to the association of ocular involvement with bleeding in locations other than epistaxis, significant association has been found only with bleeding from lesions at the mouth (age and sex adjusted $\mathrm{OR}=2.16$; 95\% CI: $1.18-3.97, p=0.01$ ) and at the skin of the nose (age and sex adjusted OR $=2.90,95 \%$ CI $1.60-5.26 p=$ 0.001 ), but not with bleeding in skin, digestive tract or central nervous system (Supplementary Table 2). The relation between eye involvement and epistaxis / nasal telangiectasias is displayed in Supplementary Table 3. Eye telangiectasias were associated with grade II intensity epistaxis (age and sex adjusted OR $=2.03$, 95\% CI: $1.04-$ 3.97, $p=0.04$ ) and with nasal telangiectasias grade ( $\mathrm{p}$ for trend $=0.001$ ); nasal telangiectasias grade III (branched telangiectasias) (age and sex adjusted $\mathrm{OR}=2.52,95 \% \mathrm{CI}$ : 1.00-6.34, $p=0.05$ ) and grade IVa (isolated vascular malformations) (age and sex OR $=3.84,95 \%$ CI: 1.20 12.3, $p=0.02$ ) displayed significant associations with ocular involvement. Finally, Supplementary Table 4 shows the association between pulmonary involvement and ocular telangiectasias. Pulmonary lesions were associated with ocular telangiectasias either when studied by bubble contrast echocardiography ( $\mathrm{p}$ for trend $=0.03$, age and sex adjusted OR for grade 4 lesions $=3.92$, 95\% CI: $1.25-12.3, \mathrm{p}=0.02)$, computerized tomography angiography (age and sex adjusted OR $=1.99,95 \%$ CI: 0.98 4.02, $p=0.06$ ) or pulmonary angiography (age and sex adjusted $\mathrm{OR}=20,95 \% \mathrm{CI}: 2.42-165.5, p=0.005$ ), although the last result was based in just 25 explorations.

\section{Discussion}

According to our results, ocular involvement in Spanish HHT patients is more frequent in people with mutations in the endoglin gene, which is responsible for HHT subtype 1 (HHT1), than in patients with mutations in the ACVRL1/ALK1 gene, responsible for HHT subtype 2 (HHT2). HHT1 has been associated with higher frequency of arteriovenous malformations located in lungs or in brain, while patients with HHT2 are more frequently affected of telangiectasias in the liver [19]. Coherently, we have found that ocular manifestations of $\mathrm{HHT}$ are associated with lung involvement as measured via bubble contrast echocardiography or computed tomography-angiography, thus ocular telangiectasias could serve as a non-invasive marker of HHT manifestations in the respiratory tract. Other signs of HHT severity, such as oral bleeding, telangiectasias in the nostril, grade of nasal telangiectasias and epistaxis intensity are also associated with ocular telangiectasias, according to

Table 3 Eye involvement and genetic mutations

\begin{tabular}{|c|c|c|c|c|}
\hline Gene & Eye involvement $(\boldsymbol{n}=105)$ & No eye involvement $(\boldsymbol{n}=101)$ & OR $(95 \% \mathrm{Cl})$ & $p$ \\
\hline$\overline{A C V R L 1 / A L K 1 ~}$ & $52(49.5 \%)$ & $66(65.3 \%)$ & 1 (reference) & - \\
\hline ENG & $48(45.7 \%)$ & $29(28.7 \%)$ & $2.10(1.12-3.95)$ & 0.01 \\
\hline MADH4 & $1(1.0 \%)$ & $0(0 \%)$ & - & - \\
\hline No mutation founded & $4(3.8 \%)$ & $6(5.9 \%)$ & $0.85(0.17-3.79)$ & 0.80 \\
\hline
\end{tabular}

ACVRL1: Activin A receptor like kinase type 1. ENG: Endoglin. MADH4 (Mother against decapentaplegic homolog 4). OR: Odds ratio. Cl: Confidence interval 
Table 4 Association of ocular telangiectasias with telangiectasias in other locations

\begin{tabular}{|c|c|c|c|c|c|c|}
\hline Telangiectasia location & & Eye involvement (yes/total) & OR $(95 \% \mathrm{Cl})$ & $p$ & $\mathrm{OR}^{\mathrm{a}}(95 \% \mathrm{Cl})$ & $p$ \\
\hline \multirow[t]{2}{*}{ Facial } & No & $41 / 96$ & 1 (Reference) & & 1 (Reference) & \\
\hline & Yes & $64 / 110$ & $1.87(1.07-3.25)$ & 0.03 & $1.45(0.78-2.69)$ & 0.24 \\
\hline \multirow[t]{2}{*}{ Nasal } & No & $5 / 14$ & 1 (Reference) & & 1 (Reference) & \\
\hline & Yes & $100 / 192$ & $1.96(0.63-6.05)$ & 0.24 & $1.45(0.46-4.64)$ & 0.53 \\
\hline \multirow[t]{2}{*}{ Lip } & No & $15 / 40$ & 1 (Reference) & & 1 (Reference) & \\
\hline & Yes & $90 / 166$ & $1.97(0.97-4.01)$ & 0.06 & $1.67(0.80-3.47)$ & 0.17 \\
\hline \multirow[t]{2}{*}{ Oral } & No & $22 / 50$ & 1 (Reference) & & 1 (Reference) & \\
\hline & Yes & $83 / 156$ & $1.45(0.76-2.75)$ & 0.26 & $1.07(0.53-2.14)$ & 0.85 \\
\hline \multirow[t]{2}{*}{ Fingers } & No & $28 / 78$ & 1 (Reference) & & 1 (Reference) & \\
\hline & Yes & $77 / 128$ & $2.70(1.51-4.83)$ & 0.001 & $2.25(1.21-4.17)$ & 0.01 \\
\hline \multirow[t]{2}{*}{ Trunk } & No & $93 / 178$ & 1 (Reference) & & 1 (Reference) & \\
\hline & Yes & $12 / 28$ & $0.69(0.31-1.53)$ & 0.36 & $0.67(0.30-1.53)$ & 0.35 \\
\hline \multirow[t]{2}{*}{ Arms } & No & $101 / 202$ & 1 (Reference) & & 1 (Reference) & \\
\hline & Yes & $4 / 4$ & - & & - & \\
\hline
\end{tabular}

$O R$ Odds ratio, $C l$ Confidence interval, $O R^{\mathrm{a}}$ Odds ratio adjusted for age at onset and sex

our results. In this regard Bergh et al., found that HHT1 subtype patients suffer of larger congenital lesions and, thus, they considered HHT 1 as a more severe phenotype [20]. On the other hand, Lesca et al. [21] studied the association of telangiectasias in lips, fingers, tongue, and nose, finding a high penetration in HHT1 with a greater number of telangiectasias in this subtype. These findings are in agreement with our results. In this same way, presumably there is an association between abnormal capillaroscopy and ocular involvement in our study because capillaroscopy is more altered in HHT1 [1].

In the only previous study analysing the relationship between conjunctival telangiectasias and HHT subtype [22], the percentages of patients with conjunctival involvement were $13.4 \%$ for HHT1 subtype and $14.6 \%$ for HHT2 subtype, which disagrees with our results. However, the ocular exploration in that study was not performed by ophthalmologists, which makes its prevalence values of ocular disease not completely comparable to ours. Other studies that have found mucocutaneous telangiectasias were unrelated to genetic mutations, either did not specify the telangiectasias location or studied them only in typical mucocutaneous locations that are considered in the Curaçao criteria, i.e., they did not consider ocular involvement $[4,19-21,23]$.

Besides that, in our study, the type of ocular lesion presented by patients with HHT are mainly telangiectasias or conjunctival vascular malformations with low rate of symptoms and only $1.12 \%$ prevalence of retinal involvement. However, we have not found any patient with retinal lesion. One of the reasons for our low retinal prevalence may be due to the fact that in the ophthalmology unit the new optical coherence tomography modality, angiographic, was not available, which could have allowed detailed study of retinal and even choroid vascularization, without the needing of using contrast. Therefore, subtle vascular retinal abnormalities may have been overlooked in the subjects who did not have fundoscopic abnormalities and, consequently, were not examined by fluorescein angiography (FA) (which is an invasive test, relegated to specific cases). However, relatively well preserved visual acuity in our cohort of participants could support that there were no retinal lesions or, as a recent article with OCT-Angiography and widefield angiography data from 24 eyes has revealed, that intraocular lesions in patients with HHT predominantly affect peripheral vasculature, while retinal vascular diseases, such as diabetes and age-related macular degeneration, typically affect the more metabolically active central vasculature of the retina [16]. Indirect ophthalmoscopy could have not been accurate enough to rule out the presence of discrete peripheral retinal telangiectasias, which can only be easily seen by UWF-FA. However, UWF-FA is an invasive test not indicated in our patients and OCT-Angiography was not available on the dates of our study. Further research with this technique in a greater number of subjects with HHT would be necessary to more accurately assess the presence of retinal lesions. Further research with this technique in a greater number of subjects with HHT would be necessary to more accurately assess the presence of retinal lesions. In addition, it is noteworthy that telangiectasias seem to have predilection for certain organs, the conjunctiva being the most affected location in the eye instead of other more vascularized locations such as the choroid. 
This study has some strengths. Firstly, all patients included in this study have a confirmed genetic diagnosis and have been followed by professionals specialized in the manifestations of the disease and its management. When Vase and Vase [17], in 1979, and Brant et al. [13] in 1989 carried out their studies on the prevalence of ocular involvement in HHT, the diagnostic criteria of Curaçao had not been established and the techniques of current genetic diagnosis were not available, so the number of patients diagnosed with HHT in their studies does not fit the current diagnostic criteria of the disease. Secondly, the HHT Unit of Hospital de Sierrallana is a reference centre for Spanish patients with HHT and the ophthalmological examination is included in the routine protocol of the HHT Unit; therefore, patients included in our study have not been selected because of suspicion of ocular involvement, which rules out selection bias. In addition, participation of ophthalmologists in one previous study in 2007 on ocular involvement [14] was carried out through questionnaires that had been submitted to the research centre.

In our series of 206 patients there are 105 patients with ocular lesions, so the prevalence of ocular involvement in our HHT population is $51 \%$. Three studies that analysed the clinical characteristics in populations of high prevalence of HHT provided much lower prevalence of conjunctival involvement, with values of $1 \%$ [24], 14\% [22] and 16\% [2]. However, these studies do not include the participation of ophthalmologists. On the other hand, five comparable prevalence studies have been published in the literature [13-17] with case series of $20,75,8,18$ and 43 , patients respectively, who have been examined by ophthalmologists, so that our study represents the one with the highest number of cases published to date. These studies estimate the prevalence of ocular involvement at 43\% [17], 35\% [13] and 38\% [14] for conjunctival lesions and 2, 10 and $0 \%$ for retinal lesions. Notice there is a big difference between the prevalence values of ocular involvement between studies published in the literature. This highlights the importance of a good examination by an ophthalmologist to confirm or rule out the existence of ocular lesions related to HHT. In addition, according to our data, patients with ocular telangiectasias were older; although, the natural history of vascular malformations in HHT patients is not well understood, this result suggests that ocular telangiectasias may appear in later stages of HHT [16].

\section{Conclusions}

Half of the patients with HHT in our study have ocular involvement. The type of ocular lesion that our patients present are mainly conjunctival telangiectasias with low rate of symptoms and are associated with HHT 1 subtype and several signs of disease severity. In addition, as the probability of eye involvement subject to mutation in ENG is higher than that in ALK1 (62.34\% vs. 44.07\%), we suggest starting the genetic sequencing with ENG if mutated, or ALK1 otherwise. Further studies are needed to confirm these results, which suggest ocular telangiectasias could be a non-invasive marker of severity in HHT.

\section{Supplementary information}

Supplementary information accompanies this paper at https://doi.org/10. 1186/s13023-020-01433-5.

Additional file 1: Supplementary Table 1. Association of ocular telangiectasias with personal history. Supplementary Table 2. Association of ocular involvement with bleeding in other locations. Supplementary Table 3. Association of ocular involvement with epistaxis characteristics. Supplementary Table 4. Association of ocular telangiectasias with lung involvement.

\section{Abbreviations}

ACVRL1: Activin A receptor like kinase type 1; ENG: Endoglin MADH4 (Mother against decapentaplegic homolog 4); OR: Odds ratio; Cl: Confidence interval

\section{Acknowledgements}

The authors thank all patients and families for their participation in the study.

\section{Authors' contributions}

Conception and design: Inés Gómez-Acebo, Sara Rodríguez Prado, Trinidad Dierssen-Sotos, Javier Llorca. Data collection: Sara Rodríguez Prado, Ángel De La Mora, Roberto Zarrabeitia Puente, Beatriz de la Roza Varela. Analysis and interpretation: Inés Gómez-Acebo, Sara Rodríguez Prado, Ángel De La Mora, Roberto Zarrabeitia Puente, Beatriz de la Roza Varela, Trinidad Dierssen-Sotos, Javier Llorca. The authors read and approved the final manuscript.

\section{Funding}

Not applicable.

\section{Availability of data and materials}

Permission to use the study database will be granted to researchers outside the study group after revision and approval of each request by the Steering Committee.

Ethics approval and consent to participate

Human subjects were included in this study. A cross-sectional study was conducted of a cohort of 206 patients studied in the HHT Unit of Hospital de Sierrallana, a reference centre for Spanish patients with HHT. The study complies with the Declaration of Helsinki and was approved by the institutional research ethics board.

\section{Consent for publication}

Not applicable.

\section{Competing interests}

The authors declare that they have no conflict of interest.

\section{Author details}

${ }^{1}$ Facultad de Medicina, Universidad de Cantabria, Avda. Herrera Oria s/n, 39011 Santander, Spain. ${ }^{2}$ IDIVAL, Santander, Spain. ${ }^{3}$ CIBER Epidemiología y Salud Pública (CIBERESP), Madrid, Spain. ${ }^{4}$ Department of Ophthalmology, Hospital Sierrallana, Torrelavega, Cantabria, Spain. ${ }^{5}$ Department of Internal Medicine, Hospital Sierrallana, Torrelavega, Cantabria, Spain. ${ }^{6}$ Centro de Investigación Biomédica en Red de Enfermedades Raras (CIBERER), Madrid, Spain 
Received: 2 March 2020 Accepted: 4 June 2020

Published online: 29 June 2020

\section{References}

1. Govani FS, Shovlin CL. Hereditary haemorrhagic telangiectasia: a clinical and scientific review. Eur J Hum Genet. 2009;17(7):860-71. https://doi.org/10. 1038/ejhg.2009.35.

2. Westermann CJJ, Rosina AF, De Vries V, de Coteau PA. The prevalence and manifestations of hereditary hemorrhagic telangiectasia in the afroCaribbean population of the Netherlands Antilles: a family screening. Am J Med Genet A. 2003;116A(4):324-8. https://doi.org/10.1002/ajmg.a.10002

3. Shovlin CL, Guttmacher AE, Buscarini E, et al. Diagnostic criteria for hereditary hemorrhagic telangiectasia (Rendu-Osler-weber syndrome). Am J Med Genet. 2000;91(1):66-7.

4. Bossler AD, Richards J, George C, Godmilow L, Ganguly A. Novel mutations in ENG and ACVRL1 identified in a series of 200 individuals undergoing clinical genetic testing for hereditary hemorrhagic telangiectasia (HHT): correlation of genotype with phenotype. Hum Mutat. 2006;27(7):667-75 https://doi.org/10.1002/humu.20342.

5. Prigoda NL, Savas S, Abdalla SA, et al. Hereditary haemorrhagic telangiectasia: mutation detection, test sensitivity and novel mutations. J Med Genet. 2006:43(9):722-8. https://doi.org/10.1136/jmg.2006.042606.

6. Abdalla SA, Geisthoff UW, Bonneau D, et al. Visceral manifestations in hereditary haemorrhagic telangiectasia type 2. J Med Genet. 2003;40(7):494502. https://doi.org/10.1136/jmg.40.7.494.

7. Abdalla SA, Pece-Barbara N, Vera S, et al. Analysis of ALK-1 and endoglin in newborns from families with hereditary hemorrhagic telangiectasia type 2 . Hum Mol Genet. 2000;9(8):1227-37. https://doi.org/10.1093/hmg/9.8.1227.

8. Letteboer TGW, Zewald RA, Kamping EJ, et al. Hereditary hemorrhagic telangiectasia: ENG and ALK-1 mutations in Dutch patients. Hum Genet. 2005;116(1):8-16. https://doi.org/10.1007/s00439-004-1196-5.

9. Lastella P, Sabbà C, Lenato GM, et al. Endoglin gene mutations and polymorphisms in Italian patients with hereditary haemorrhagic telangiectasia. Clin Genet. 2003;63(6):536-40. https://doi.org/10.1034/j.13990004.2003.00081.x

10. Olivieri $C$, Mira $E$, Delù $G$, et al. Identification of 13 new mutations in the ACVRL1 gene in a group of 52 unselected Italian patients affected by hereditary haemorrhagic telangiectasia. J Med Genet. 2002;39(7):E39. https:// doi.org/10.1136/jmg.39.7.e39.

11. Lesca G, Plauchu H, Coulet F, et al. Molecular screening of ALK1/ACVRL1 and ENG genes in hereditary hemorrhagic telangiectasia in France. Hum Mutat. 2004;23(4):289-99. https://doi.org/10.1002/humu.20017.

12. Fernandez-L A, Sanz-Rodriguez F, Zarrabeitia R, et al. Mutation study of Spanish patients with hereditary hemorrhagic telangiectasia and expression analysis of Endoglin and ALK1. Hum Mutat. 2006;27(3):295. https://doi.org/ 10.1002/humu.9413.

13. Brant AM, Schachat AP, White RI. Ocular manifestations in hereditary hemorrhagic telangiectasia (Rendu-Osler-weber disease). Am J Ophthalmol. 1989;107(6):642-6. https://doi.org/10.1016/0002-9394(89)90261-4.

14. Geisthoff UW, Hille K, Ruprecht KW, Verse T, Plinkert PK. Prevalence of ocular manifestations in hereditary hemorrhagic telangiectasia. Graefes Arch Clin Exp Ophthalmol Albrecht Von Graefes Arch Klin Exp Ophthalmol. 2007; 245(8):1141-4. https://doi.org/10.1007/s00417-006-0520-2.

15. Rinaldi M, Buscarini $E_{\text {, Danesino }}$, et al. Ocular manifestations in hereditary hemorrhagic telangiectasia (Rendu-Osler-weber disease): a case-series. Ophthalmic Genet. 2011;32(1):12-7. https://doi.org/10.3109/13816810.2010. 535891

16. Sindhar S, O'Bryhim BE, Licata J, Piccirillo JF, Apte RS. Identification of retinal vascular lesions using ultra-Widefield angiography in hereditary hemorrhagic telangiectasia patients. Ophthalmol Retina. 2019;3(6):510-5. https://doi.org/10.1016/j.oret.2019.02.004.

17. Vase I, Vase P. Ocular lesions in hereditary haemorrhagic telangiectasia. Acta Ophthalmol. 1979;57(6):1084-90.

18. ARUP Scientific Resource for Research and Education: HHT Disease Databases | University of Utah. http://arup.utah.edu/database/HHT/. Accessed August 21, 2019.

19. Bayrak-Toydemir P, McDonald J, Markewitz B, et al. Genotype-phenotype correlation in hereditary hemorrhagic telangiectasia: mutations and manifestations. Am J Med Genet A. 2006;140(5):463-70. https://doi.org/10. 1002/ajmg.a.31101.
20. Bergh J, Jönsson PE, Glimelius B, Nygren P, SBU-group. Swedish Council of Technology Assessment in health care. A systematic overview of chemotherapy effects in breast cancer. Acta Oncol Stockh Swed. 2001;40(23):253-81.

21. Lesca G, Olivieri C, Burnichon N, et al. Genotype-phenotype correlations in hereditary hemorrhagic telangiectasia: data from the French-Italian HHT network. Genet Med. 2007;9(1):14-22. https://doi.org/10.1097/gim. Ob013e31802d8373.

22. Letteboer TGW, Mager H-J, Snijder RJ, et al. Genotype-phenotype relationship for localization and age distribution of telangiectases in hereditary hemorrhagic telangiectasia. Am J Med Genet A. 2008;146A(21): 2733-9. https://doi.org/10.1002/ajmg.a.32243.

23. Sabbà C, Pasculli G, Lenato GM, et al. Hereditary hemorrhagic telangiectasia: clinical features in ENG and ALK1 mutation carriers. J Thromb Haemost JTH. 2007:5(6):1149-57. https://doi.org/10.1111/j.1538-7836.2007.02531.x.

24. Plauchu H, de Chadarévian JP, Bideau A, Robert JM. Age-related clinical profile of hereditary hemorrhagic telangiectasia in an epidemiologically recruited population. Am J Med Genet. 1989;32(3):291-7. https://doi.org/10. 1002/ajmg.1320320302.

\section{Publisher's Note}

Springer Nature remains neutral with regard to jurisdictional claims in published maps and institutional affiliations.
Ready to submit your research? Choose BMC and benefit from:

- fast, convenient online submission

- thorough peer review by experienced researchers in your field

- rapid publication on acceptance

- support for research data, including large and complex data types

- gold Open Access which fosters wider collaboration and increased citations

- maximum visibility for your research: over $100 \mathrm{M}$ website views per year

At $\mathrm{BMC}$, research is always in progress.

Learn more biomedcentral.com/submissions 